\title{
A Libras como Proposta Educacional no Ensino Bilingue para Alunos com Surdez no Município de Belém
}

\author{
Cydriane Cristina Araújo de Sousa ${ }^{1}$; Bethânia Alves Sena ${ }^{2}$; Marilene dos Santos Marques ${ }^{3}$
}

Resumo: O presente trabalho constitui-se em um recorte de pesquisa bibliográfica mais ampla que objetivou analisar a sobre a temática da Língua Brasileira de Sinais (LIBRAS) como Proposta Educacional no Ensino Bilíngue para alunos com surdez no município de Belém. Dessa forma, o trabalho discute como está sendo atribuídas as práticas educativas. Nesse sentido, levantou-se o seguinte questionamento acerca de que forma os alunos com surdez estão utilizando as propostas educativas nas series iniciais? No que diz respeito à literatura pesquisada com conhecimentos de alguns estudiosos da área, entre eles: Ferreira (2006) Lacerda (2000) Skilar (1999) Sanches(1993). Assim, buscou-se pensar numa inclusão para todos, onde surdos e ouvintes possam e devam aprender juntos caracterizando, dessa forma, um movimento eficaz dentro da educação inclusiva.

Palavras-Chave: Formação Docente, Bilinguismo, Língua de Sinais.

\section{The Brazilian Sign Language as an Educational Proposal in Bilingual Education for Students with Deafness in the Municipality of Belém}

\begin{abstract}
The present work constitutes a more extensive bibliographical research that aimed to analyze the thematic of the Brazilian Sign Language (LIBRAS) as Educational Proposal in Bilingual Education for students with deafness in the city of Belém. Thus, the paper discusses As being attributed to educational practices. In this sense, the following question was raised about which educational proposals are being used for students with deafness in the initial series, regarding the literature researched with knowledge of some scholars in the area, among them: Ferreira (2006) Lacerda 2000) Skilar (1999) Sanches (1993). Thus, we sought to think of an inclusion for all, where deaf and hearing can and should learn together, thus characterizing an effective movement within inclusive education.
\end{abstract}

Keywords: Teacher Training, Bilingualism, Sign Language.

\section{Introdução}

O bilinguismo surgiu para tornar eficaz o aprendizado dos alunos com surdez, visto que prioriza a Libras em todas as situações, enquanto o português escrito é ensinado como segunda língua (ALBANO, 2012).

\footnotetext{
${ }^{1}$ Licenciada em História, e Especialista em Educação Especial na Perspectiva da Inclusão e Língua Brasileira de Sinais (LIBRAS) pela Faculdade Integrada Ipiranga. cydri.libras@yahoo.com.br;

${ }^{2}$ Bióloga, Mestre em Ecologia aquática e aquicultura, no Programa Ciência Animal, na Universidade Federal do Pará. Tradutora e Intérprete de Linguagem de Sinais no Instituto Federal do Pará. betalsena@yahoo.com.br;

${ }^{3}$ Prof ${ }^{\mathrm{a}}$ M.s.C em Gestão e desenvolvimento Regional; Orientadora do artigo pelas Faculdades Integradas Ipiranga. marquesmarilene@hotmail.com
} 
A educação de surdos é um termo pertinente, sendo que as comunidades surdas, junto com os pesquisadores buscam debater a importância de se ofertar uma educação o e uma perspectiva bilíngue para surdos. É fato que as últimas décadas foram importantes para um melhor entendimento das necessidades educacionais de alunos surdos e particularmente quanto ao avanço de políticas públicas nessa direção, uma vez, que essas políticas voltadas para o aluno surdo são necessárias, porque podem investigar a busca de melhores condições de aprendizagens para tal educando. E a escola precisa adquirir padrões indicados pelas políticas públicas e, deixar de ocultar alguns dos padrões.

Além da necessidade de políticas públicas mais direcionadas é sinalizado também o interesse e a necessidade pela formação de futuros profissionais cientes da condição linguística, diferenciada dos alunos surdos. Neste contexto analisa-se a importância da formação do professor para o ensino da Libras (Língua Brasileira de Sinais), viabilizando a formação bilíngue.

As reflexões acerca da formação de professores vêm se destacando muito nas conferências e nos seminários sobre educação desde o final da década de 1970, época que se iniciou um movimento de discussões sobre a escola brasileira, a preocupação com o fracasso escolar levou a series de discussões e análises dos fatores responsáveis pela baixa qualidade de ensino aponta a certeza que mudanças precisam ser implantadas o quanto antes.

O sistema público brasileiro reconhece a diferença linguística do surdo como importante fator de identidade cultural, valorizando a língua de sinais. No entanto ainda se busca meios para ensiná-la nas escolas, a exemplo de tantos outros países. Por isso o presente trabalho tem como objetivo investigar de uma maneira mais confortável a necessidade de se repensar que práticas metodológicas podem ser utilizadas pelo surdo.

\section{Material e Métodos}

A metodologia do presente artigo se deu, basicamente, pela pesquisa bibliográfica que segundo GIL (2012, p. 29) é elaborada com base em material já publicado. O presente estudo permite uma discussão acerca das propostas metodológicas segundo a literatura dos estudiosos Bueno(1993) Carneiro(1997) Ferreira(2006) Goncalves(2004) Lacerda(2000) Sá(1999) Skilar(1999) (1997) Sanches(1993) Unesco(1994) Carneiro(1997). 


\section{A importância da formação docente para uma boa prática educacional bilingue}

A formação continuada dos professores representa um papel importantíssimo na transformação escolar à educação a cada dia mais diversificada e mais ampla acaba exigindo do professor uma prática mais pedagógica que alcance um mundo multicultural dos surdos.

Nesse contexto a disciplina de Língua Brasileira de Sinais (Libras), visa possibilitar a inclusão efetiva dos alunos surdos nas salas de aula do ensino regular exigindo professores com formação continuada adequada para o trabalho pedagógico. Logo a formação continuada com ações de capacitação dos profissionais é de extrema necessidade pôr em foco as metodologias para o ensino para surdos priorizando os aspectos visuais que caracterizam comportamentos inviáveis de alunos que não aprendem. Afinal o maior desafio não é incluir o aluno com necessidades especiais, e sim acreditar que ele possa de alguma maneia aprender, desde que todos estejam dispostos e preparados para ensinar.

Dentro desse contexto a formação de professores ganha um traçado mais complexo quando se pensa em formar docentes para atender as necessidades da educação especial, pois nada serve se os profissionais de modo geral da educação não estiverem preparados de forma adequada para atuar com alunos com demandas especificas.

O interessante é que o professor possa alcançar as metas previstas relativas ao desempenho e as capacidades intelectuais dos alunos, e cabe a ele e à educação escolar abrir caminhos da sensibilidade humana para tornar apta a ideia de aprender a viver juntos e de uma educação para todos. Dentro desse contexto (CARNEIRO, 1997) contribui dizendo que a escola é o lugar próprio da sociedade para o desenvolvimento da aprendizagem, da solidariedade e dos direitos e deveres que ligam as pessoas entre si.

Para essa investigação nos interessa o professor que atue nas Escolas Educação bilingues, pois uma Proposta de Educação Bilíngue, para os surdos propõe que a língua de sinais como primeira língua dos surdos.

A Lei Federal 10.436, de 24 de abril de 2002, reconhece a língua de sinais em todo o país. Ela foi regulamentada e os fundamentos foram publicados através do decreto governamental 5.626 de 22 de dezembro de 2005, tornando obrigatório o uso da língua de sinais não somente para os surdos, mas também para os professores que atendem esses alunos além de disciplinar a presença de intérpretes de Libras. 
Esse decreto provocou mudanças nas instituições formadoras de professores que tendo de cumprir o que essa lei determinava, foi trazendo a Libras para as instituições de ensino superior, disseminando o seu uso, e conhecendo- a cada vez mais através da geração de pesquisas. Esse decreto determinou a inclusão da Libras como disciplina curricular assim proposto.

Hoje em dia, se vê como mais frequência a Língua de Sinais sendo aceita pelos ouvintes e sendo vista como peça importante no processo educacional dos surdos. Apesar de toda essa busca de aceitação o que ainda se percebe é que a Língua de Sinais ainda é vista como instrumento para se atingir a oralização na tentativa de transformar o surdo em ouvinte, que de modo geral se tornaria um fracasso. Enfim o que os ouvintes precisam compreender é que aceitar a Língua de Sinais é também aceitar a surdez como diferença.

\section{Bilinguismo: um grande desafio}

A proposta bilíngue traz uma grande contribuição para o desenvolvimento da criança surda, onde visa permitir que o aluno surdo, construa uma autoimagem positiva, pois além de utilizar a língua de sinais como língua materna, terá também a possibilidade de recorrer à língua portuguesa para inseri-lo na cultura ouvinte onde irá favorecer o desenvolvimento cognitivo e a ampliação de vocabulário da criança surda. No entanto é fundamental que a criança adquira primeira a língua de sinais e depois a língua portuguesa. Autores como Sanches (1993) acredita ser necessário para o surdo adquirir a língua de sinais e a língua oficial do seu país apenas na modalidade escrita e não oral, até mesmo para que ajude inteiramente na compreensão de qualquer contexto.

Ao encontrarmos com a pessoa surda, logo pensamos em ensino diferente, separado do aluno ouvinte. No entanto todos devem ter os mesmos direitos no que se refere à aprendizagem e o papel da escola é estimular o potencial de cada um seja no cognitivo; linguístico ou cultural contribuindo para o desenvolvimento e aprendizagem e o critério da inclusão é à base da ideia de uma só escola para todos, ou seja, se o mundo é de todos, à escola não pode ser de alguns.

O que se percebe no contexto educacional é que as práticas metodológicas e de avaliação que são aplicadas para o aluno ouvinte são as mesmas usadas com o aluno surdo, buscando 
ainda os mesmos resultados em vez de buscarem novas propostas educacionais que venham colaborar para o processo de desenvolvimento do ensino-aprendizagem.

Muitos fatores ainda comprometem a adoção do bilinguismo, falta a estrutura adequada para sua utilização. A educação inclusiva tem como intuito uma única escola para todos. Desta forma a busca da implantação da proposta bilíngue requer que vários fatores sejam repensados como a formação do docente já questionada acima, nova tecnologia educacional relativo aos recursos visuais e a inquietação quanto à aprendizagem da Língua Portuguesa, e o Estado neste caso devem disponibilizar todos os meios e recursos para que as pessoas com deficiência possam acompanhar e complementar a educação escolar. É importante salientar também que não bastam apenas mudanças nos mecanismo histórico, político cultural etc. É necessário compreender que tal objetivo possa ser alcançado.

Mediante estudos sobre a educação bilíngüe como o de Skilar (1999) surge novas propostas que aparecem no contexto educacional, inclusive a possibilidade de inserção do interprete em sala de aula como aponta Lacerda (2000) Muitos compartilham da ideia da urgência de construirmos alianças entre as diversas análises dessa realidade que vem desafiando todos nós, ou seja, a fabricação de outras formas de experiências que possamos ter de nós mesmos, dos outros e do mundo só se concretizará se formos capazes de forjar conceitos e práticas que possam construir uma realidade mais múltipla e solidária.

A Lei 10.436/2002 reconhece a Língua Brasileira de Sinais (Libras) para a comunicação e expressão com deficientes auditivos A partir da Lei e do Decreto de Libras a oferta de educação bilíngue passa a ser organizada pelos sistemas de ensino, como direito dos alunos surdos, fundamental ao exercício da cidadania. Os educandos surdos passam a serem modelos de identificação linguístico-cultural, exercendo papeis significativos na comunidade escolar. A Libras como $1^{\mathrm{a}}$ Língua e a Língua Portuguesa como $2^{\mathrm{a}}$ língua.

Sabemos que as criações dessas Leis tanto federais, quantos estaduais e municipais, são muito significativas, mas e claro que precisam ser ampliadas, pois muitas coisas precisam melhorar.

Dentro desse contexto espera-se que o professor possua capacitação profissional a fim de possibilitar sua aprendizagem. Nos últimos anos, com as mudanças na sociedade e as mudanças na própria legislação, permitiu-se criar a oportunidade da inclusão de pessoas com deficiência. 


\section{Bilinguismo no Município de Belém}

Sabemos que a escola além de ser um espaço de construção de sua identidade, fora do ambiente familiar. Contudo, essa escola não é oferecida para todos, como determina as legislações, uma vê que ainda há de milhares de crianças a margem da sociedade.

E como anda o esclarecimento quanto à concepção do bilinguismo e o domínio de metodologias adequadas no município de Belém? A partir de estudo-piloto feito por (Gonçalves 2004), no município de Oriximiná e Óbidos, ambos localizados no Oeste do Pará, Baixo Amazonas é perceptível a procura considerável de alunos surdos referentes a outras deficiências, uma vez que de $100 \%$ dos alunos surdos que entravam nas escolas apenas $20 \%$ finalizavam seus estudos, ou seja, as maiorias dos alunos acabam evadindo ou por não conseguirem acompanhar a turma, ou pelo fato de não saberem ler, escrever ou compreender a língua portuguesa e nem a sua própria língua (LIBRAS) que constitui a sua identidade de cultura surda.

Dentro do município de Belém muito se tem a fazer, pois congressos são organizados, mesas redondas são bem discutidas e palestras são bem exibidas mais afinal qual o objetivo dessas apresentações se dentro do município de Belém não há se quer uma escola bilingue que sirva de referência para tantas discussões! Afinal quais as necessidades ainda existentes quanto à educação bilíngue de surdos nos municípios de Belém, tendo em vista a grande importância deste método para o desenvolvimento integral do sujeito surdo?

O que se observa é que a inclusão da pessoa com deficiência na escola regular está prevista em lei, mas continua sendo um desafio e gerando polêmica, ninguém se forma no vazio. Formar-se, supõe troca de experiências, aprendizagens, interações sociais etc. É necessário que as escolas regulares do município de Belém garantam a oferta de educação bilíngüe_em Libras como primeira língua e na modalidade escrita da Língua portuguesa como segunda língua.

\section{Conclusões}

Percebe-se que a educação bilíngue ainda parece ser um projeto irreal, porém, não podemos desconsiderar que, embora inseridas na perspectiva da educação especial dos surdos, essa parcela de professores, estão enraizadas por uma formação que não considerava as 
diferenças no processo educativo e viam a normatização como um modo de inserir os surdos na sociedade. Podemos chegar à conclusão de que houve mudanças positivas a respeito da inclusão de surdos na sociedade, mais existem ainda grandes desafios a serem enfrentados. Um deles e criar uma proposta educacional bilíngue que atinja toda a população.

Neste contexto as escolas devem ser restruturadas para que os professores tenham condições de se capacitarem para atender todos os alunos de modo igual, onde transformar a construção da escola bilíngue para surdos e todos os desdobramentos pra que ela aconteça isso envolve constitutivamente a formação de professores e práticas metodológicas bilíngües que compreendam as diferenças educacionais dos alunos surdos e ouvintes, para que possam ser ajudados através do desenvolvimento de estratégias pedagógicas que atendam essas diferenças.

\section{Referências}

ALBANO, Alexandra Maria dos Santos. Bilinguismo. Editora FAEL. Curitiba. 2012.

BUENO, J.G.S. Educação Especial Brasileira: Integração/ Segregação do aluno diferente. São Paulo: EDUC, 1993.

BRASIL, Ministério da Educação. Secretaria de Educação Especial. Política Nacional de Educação Especial na Perspectiva da Educação Inclusiva. Brasília: MEC/SEESP, 2008. Disponível em: <htpp: //portal.mec.gov.br/seesp/arquivos/pdf/política.pdf>. Acesso em: 17 de abr.2011.

CARNEIRO, Rogéria. Sobre a Integração de Alunos Portadores de Deficiência no Ensino Regular. Revista Integração. Secretaria de Educação Especial do MEC, 1997.

Lei $n^{\circ}$ 10.436, de 24 de abril de 2002. Dispõe sobre a Língua Brasileira de Sinais - Libras e da outras providencias. Brasília: Senado Federal, 2002, Disponível em <http://www.planalto.gov.bc/ccivil_03/LEIS/2002/L10436. Acesso em: 25 abr. 2014.

FERREIRA, Windyz. Inclusão x Exclusão no Brasil: reflexões sobre a formação docente dez anos após Salamanca. In: David Rodrigues (Org.). Inclusão e educação: Doze olhares sobre a educação inclusiva. 1. ed. São Paulo: Summus Editorial, 2006,p. 211-238.

LACERDA, C.B.F.de . A Criança surda e a língua de sinais no contexto de uma sala de aula de alunos ouvintes. Relatório Final FAPESP Proc. nº 98/02861-1, São Paulo: Editora Lovise, 2000.

Ministério da Educação. Referencial Curricular para a Educação infantil: estratégia e orientações para a educação de crianças com necessidades educacionais especiais. Brasília: MEC, 2000. 
SANCHES, C. Vida para os surdos. Revista Nova Escola. Rio de Janeiro: Abril, 1993. SÁ, NRL. Educação de Surdos: A Caminho do Bilinguismo. Niterói: EDUFF; 1999. SASSAKI, R.K. Inclusão: construindo uma sociedade para todos. Rio de Janeiro: WVA, 1997.

SKLIAR, C. A localização política da educação bilíngue para surdos. In: Atualidades para educação bilíngue para surdos. Porto Alegre: Editora Mediação, 1999.

STROBEL, K. As imagens do outro sobre a cultura surda. Florianópolis: Editora da UFSC, 2008.

UNESCO. Declaração de Salamanca e linha de ação sobre as necessidades educacionais: nas áreas das necessidades educativas especiais. Brasília: UNESCO, s/l, 1994.

\section{Como citar este artigo (Formato ABNT):}

SENA, Bethânia Alves. A Libras como Proposta Educacional no Ensino Bilingue para Alunos com Surdez no Município de Belém. Id on Line Rev.Mult. Psic., 2018, vol.12, n.42, Supl. 1, p. 503-510. ISSN: 1981-1179.

Recebido: 08/11/2018;

Aceito: 12/11/2018 